\title{
Síndrome de Peutz-Jeghers e acalásia: relato de caso e revisão da literatura
}

\author{
Peutz-Jeghers syndrome and achalasia: case report and literature review
}

\author{
Luís Felipe de Almeida Okida1, Ana Teresa Pugas Carvalho², Paulo Roberto Alves de Pinho
}

Okida LFA, Carvalho ATP, Pinho PRA. Síndrome de Peutz-Jeghers e acalásia: relato de caso e revisão da literatura / Peutz-Jeghers syndrome and achalasia: case report and literature review. Rev Med (São Paulo). 2017 jul.-set.;96(3):197-203.

RESUMO: A síndrome de Peutz-Jeghers (SPJ) é uma doença autossômica dominante rara, caracterizada pela presença de pólipos hamartomatosos gastrointestinais e máculas hipercrômicas mucocutâneas. O presente trabalho relata um caso de um paciente com máculas hipercrômicas na região labial, palmar e plantar, além de pólipos gastrointestinais hamartomatosos, sendo diagnosticado com SPJ, e que evoluiu com quadros de dor abdominal intensa, dois episódios de intussuscepção e aparecimento de acalásia. Além da associação inédita na literatura, até onde se sabe, de SPJ com acalásia, o seguinte trabalho traz uma revisão da literatura sobre a doença, bem como recomendação no rastreio de câncer em tais pacientes, dado que apresentam maior risco de desenvolver neoplasias malignas.

Descritores: Síndrome de Peutz-Jeghers; Polípos intestinais; Acalasia esofágica; Intussuscepção; Neoplasias gastrointestinais/ diagnóstico; Neoplasias/diagnóstico.

\begin{abstract}
Peutz-Jeghers syndrome (PJS) is a dominant autosomal rare disease, characterized by gastrointestinal hamartomatous polyps and mucocutaneous hyperchromic macules. The present study reports a case of a patient with hyperchromic macules in the labial, palmar and plantar regions, as well as gastrointestinal hamartomatous polyps, being diagnosed with PJS, and evolving with episodes of intense abdominal pain, two episodes of intussusception and the appearance of achalasia. In addition to the unpublished association in the literature, as far as is known, of PJS and achalasia, the following work brings a review of the literature on the disease, as well as recommendation in the cancer screening in such patiens, since they are at higher risk of developing malignant neoplasms.
\end{abstract}

Keywords: Peutz-Jeghers syndrome; Intestinal polyps; Esophageal achalasia; Intussusception; Gastrointestinal neoplasms/diagnosis; Neoplasms/diagnosis.

1. Acadêmico de medicina, Faculdade de Ciências Médicas, Universidade do Estado do Rio de Janeiro (UERJ), Rio de Janeiro, RJ, BR. Email: felipeokida@gmail.com.

2. Professora associada da disciplina de Gastroenterologia e Endoscopia Digestiva, Hospital Universitário Pedro Ernesto, Universidade do Estado do Rio de Janeiro (UERJ), Rio de Janeiro, RJ, BR. Email: atpugas@yahoo.com.br.

3. Professor associado da disciplina de Gastroenterologia e Endoscopia Digestiva, Hospital Universitário Pedro Ernesto, Universidade do Estado do Rio de Janeiro (UERJ), Rio de Janeiro, RJ, BR. Email: pinho@cmb.com.br.

Endereço para correspondência: Faculdade de Ciencias Médicas da UERJ - Hospital Universitário Pedro Ernesto. Boulevard Vinte e Oito de Setembro, 77 - $3^{\circ}$ andar - Gastroenterologia. Vila Isabel, Rio de Janeiro, RJ, Brasil. CEP: 20.551-030. 


\section{INTRODUÇÃO}

síndrome de Peutz-Jeghers (SPJ) é uma doença autossômica dominante clinicamente caracterizada por pólipos gastrointestinais hamartomatosos, máculas hipercrômicas mucocutâneas e predisposição a algumas neoplasias, como câncer colorretal e gástrico. A doença afeta homens e mulheres na mesma proporção, bem como não há maior prevalência em determinado grupo racial ou étnico. Trata-se de uma doença rara, com estimativas de prevalência variando entre 1:50.000 e $1: 200.000^{1}$.

O seguinte trabalho tem como objetivo relatar um caso de um paciente com máculas hipercrômicas em região labial, palmar e plantar, pólipos hamartomatosos no intestino delgado, região colorretal e estômago, além de dois episódios de intussuscepção que demandaram ressecção segmentar de mais de 30 centímetros do intestino delgado. Foi submetido a diversas polipectomias, a exames de imagem, como colonoscopia e endoscopia digestiva alta, sendo o diagnóstico de SPJ confirmado somente na terceira década de vida. Além disso, tal paciente apresentou um quadro de disfagia de condução, o que levou ao diagnóstico de acalásia.

Até o presente momento, por ser uma doença rara, existem poucos relatos de caso sobre tal desordem, sendo que não existe relatado na literatura médica acerca de um paciente com SPJ e acálasia, sendo, portanto, um caso inédito já registrado. Além disso, foi feita uma revisão da literatura, abrangendo a recomendação no rastreio de câncer em tais pacientes, visto que apresentam maior chance no desenvolvimento de neoplasias malignas de região colorretal, mama, pâncreas, aparelho reprodutor, intestino delgado, pulmão e região gastroesofagiana.

\section{RELATO}

Paciente masculino, 29 anos, pardo, solteiro, marmorista, ensino fundamental completo, evangélico, natural do Rio de Janeiro, reside no bairro de Jacarepaguá.

Aos 17 anos de idade apresentou quadro de dor abdominal aguda e espontânea de forte intensidade, em cólica, difusa, sem irradiação, sem fatores atenuantes, agravada à deambulação, associada à parada de eliminação de gases e fezes, sem febre e demais sintomas. Procurou o Hospital Universitário Pedro Ernesto (HUPE) - UERJ. Informou apresentar diminutas lesões hiperpigmentadas, acastanhadas e não coalescentes, distribuídas em lábio inferior desde os dois anos de idade. Evoluiu com o aparecimento de novas lesões semelhantes em regiões palmares e plantares com o passar dos anos. Relatou que uma irmã, aos 19 anos de idade, apresentou quadro clínico semelhante com dor abdominal, tendo evoluído a óbito sem diagnóstico estabelecido. Tal irmã não apresentava qualquer tipo de máculas mucocutâneas em região oral, palmar e plantar. Desconhecia saúde materna e paterna, três irmãos hígidos e avó materna com SPJ. Negava tabagismo, etilismo, demais comorbidades, alergias, transfusões e cirurgias prévias.

Ao exame físico, paciente encontrava-se em regular estado geral, lúcido e orientado no tempo e espaço, fácies de dor, normocorado, anictérico, acianótico, eupneico em ar ambiente, hidratado, afebril ao toque. Apresentava múltiplas máculas hipercrômicas não coalescentes de coloração acastanhada, variando entre 1 a $3 \mathrm{~mm}$ de diâmetro, principalmente no lábio e mucosa labial inferior. Região gengival preservada. Exame neurológico, pulmonar e cardiovascular sem alterações, apresentando dor abdominal à palpação profunda, sem sinais de irritação peritoneal. Além disso, presença de múltiplas máculas hipercrômicas acastanhadas não coalescentes em regiões palmo-plantar, variando de 1 a $4 \mathrm{~mm}$ de diâmetro. Exames laboratoriais inalterados.

No HUPE-UERJ o paciente foi submetido à colonoscopia, a qual identificou 5 pólipos colorretais, sendo realizadas polipectomias. Também foi submetido à endoscopia digestiva alta (EDA) que identificou pólipos gástricos, com consequente polipectomias. Manteve consulta ambulatorial para monitoramento dos múltiplos pólipos.

Aos 24 anos de idade, paciente apresentou novamente quadro de dor abdominal intensa difusa, de caráter progressivo, espontânea, sem irradiação, em cólica, procurando o HUPE-UERJ. Foi feita enterografia por tomografia computadorizada, na qual foi constatada intussuscepção intestinal, e então realizada terapêutica cirúrgica com enterectomia segmentar, além de polipectomias no intestino delgado. A análise histopatológica macroscópica evidenciou formações polipoides de tecido pardacento e, microscopicamente, pólipos hamartomatosos do tipo Peutz-Jeghers não apresentando malignidade.

O quadro agudo foi corrigido, o paciente foi estabilizado e encaminhado para alta hospitalar. Duas semanas depois, paciente apresentou o mesmo quadro, sendo feita nova enteroscopia, evidenciando nova intussuscepção. Foi feita uma laparotomia de urgência, mas sem necessidade de enterectomia segmentar. Novamente, o paciente foi estabilizado e encaminhado para alta hospitalar.

Aos 25 anos, o paciente apresentou dor abdominal associada à ingestão de alimentos sólidos. Procurou o HUPE-UERJ e foi submetido à enteroscopia, sendo ressecado um pólipo de jejuno proximal. Mesmo assim, a dor se manteve e paciente apresentou perda ponderal de 20 quilos, evoluindo com desnutrição. Submetido à nutrição parenteral e à nova enteroscopia, a qual evidenciou 5 pólipos pediculados e 5 pólipos sésseis em intestino delgado, além de estenose tubular de jejuno, sugestivo de isquemia associada à invaginação prévia. Uma nova laparotomia foi necessária, com ressecção de 
30 centímetros de extensão do intestino delgado (jejuno), além de realizadas três polipectomias por via endoscópica. $\mathrm{Na}$ análise histopatológica, novamente as formações polipoides eram pardacentas e pediculadas, com padrão hamartomatoso tipo Peutz-Jeghers.

Após 8 meses do quadro cirúrgico, o paciente iniciou quadro de disfagia de condução e vômitos alimentares precoces (de conteúdo alimentar após refeições), além de perda ponderal de 5 quilos. Realizou EDA, a qual evidenciou grande quantidade de resíduo alimentar, sólido e líquido, em toda extensão do corpo esofagiano, impedindo o prosseguimento do endoscópio para o estômago. Depois de 4 dias, com a melhora do preparo, nova EDA foi feita, identificando megaesôfago grau III, pólipos gástricos (Yamada I) e áreas de atrofia focal no corpo gástrico. $\mathrm{O}$ paciente foi então submetido à esofagomanometria, confirmando acalásia. Na ocasião, negava viagens recentes e já ter tido contato com insetos da subfamília Triatominae ("barbeiro"), apesar de residir previamente em moradia de pau a pique. Foi realizada, então, dilatação pneumática da cárdia, e o paciente foi encaminhado para alta hospitalar, seguindo em acompanhamento ambulatorial pelo serviço de gastroenterologia do HUPE-UERJ.

\section{DISCUSSÃO}

A síndrome de Peutz-Jeghers (SPJ) é uma doença autossômica dominante atribuída à mutação no gene STK11/LKB1 e é clinicamente caracterizada por pólipos gastrointestinais hamartomasos, máculas hipercrômicas mucocutâneas, além de predisposição a algumas neoplasias. A doença afeta homens e mulheres na mesma proporção, bem como não há maior prevalência em determinado grupo racial ou étnico. Trata-se de uma doença rara, com estimativas de prevalência variando entre 1:50.000 e $1: 200.000^{1}$.

A associação de pólipos hamartomatosos gastrointestinais, principalmente em intestino delgado, com máculas hiperpigmentadas em região mucocutânea foi reconhecida pela primeira vez por Jan Peutz em $1921^{2}$. Em 1949, Harold Jeghers et al. ${ }^{3}$ revisaram alguns casos e confirmaram a associação antes feita por Peutz, configurando o epônimo da síndrome em questão.

A SPJ ocorre devido a uma mutação do gene STK11, também conhecido como LKB1, o qual se encontra na região cromossômica $19 \mathrm{p} 13.3^{4}$. O gene situado em tal locus está envolvido com a codificação de uma serina-treonina quinase (serine/threonine kinase 11/liver kinase B1) e parece atuar como um gene supressor de tumor. Uma vez que a mutação é identificada no paciente com SPJ, deve-se submeter familiares ao teste específico de verificação da mutação a fim de determinar se a doença está presente e iniciar o rastreamento indicado. A mutação no gene STK11/ LKB1 está presente aproximadamente em 30 a $70 \%$ dos casos esporádicos da SPJ e em 70\% dos pacientes com a síndrome associada à história familiar ${ }^{5}$. Desse modo, algumas pessoas podem não apresentar mutação no gene STK11/LKB1 e mesmo assim apresentar a SPJ. Isso sugere que existem outros genes envolvidos por trás.

O diagnóstico da SPJ pode ser feito através da presença de um ou mais pólipos hamartomatosos associado a dois ou mais dos seguintes achados: máculas hipercrômicas labiais, história familiar de SPJ ou pólipos em intestino delgado. A média de idade ao diagnóstico da síndrome é de 23 anos de idade em homens e 26 em mulheres ${ }^{5}$.

\section{Manifestações clínicas}

A SPJ pode ocorrer de forma esporádica ou de forma autossômica dominante hereditária, e em ambas há heterogeneidade na forma de apresentação clínica. Cerca de $95 \%$ dos pacientes com a síndrome apresentam hiperpigmentação mucocutânea caracterizada por pequenas máculas hipercrômicas, variando entre 1 a 5 milímetros de diâmetro, geralmente distribuídas nos lábios, mucosa oral, língua, olhos, narinas, região perianal e, menos comumente, nos quirodáctilos, pododáctilos, mãos e pés ${ }^{4}$. Tais manchas podem estar presentes desde o nascimento ou se apresentarem nos primeiros meses de vida, sendo que em alguns casos podem desaparecer na adolescência ou fase adulta. No entanto, normalmente as máculas na mucosa bucal persistem. Vale ressaltar que as lesões pigmentares da SPJ não estão associadas à transformação neoplásica.
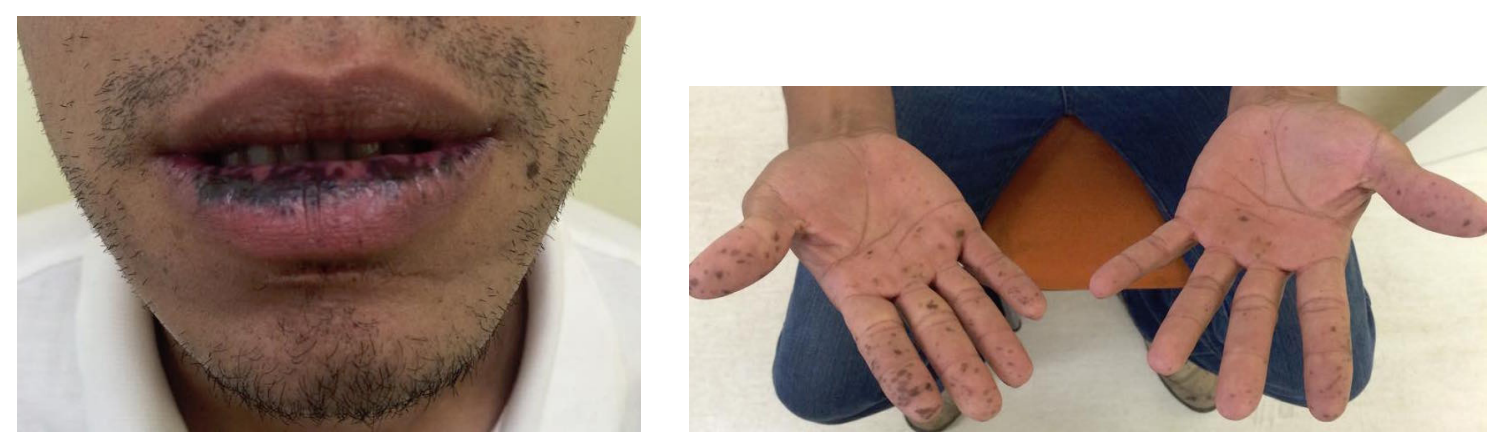

Figura 1. Paciente do caso clínico apresentando máculas hipercrômicas no lábio inferior e na região palmar 
Okida LFA, et al. Síndrome de Peutz-Jeghers e acalásia: relato de caso e revisão da literatura.

No trato gastrointestinal, a presença de pólipos hamartomatosos é essencial para a confirmação da SPJ. Cerca de $90 \%$ dos pacientes com SPJ apresentam pólipos e normalmente o processo se inicia entre 11 e 13 anos de idade, mais comumente no intestino delgado (jejuno, íleo e duodeno, por ordem decrescente de acometimento), seguido por cólon, reto e estômago ${ }^{3}$. Os pólipos intestinais são usualmente pedunculados e largos, o que favorece a ocorrência de episódios recorrentes de intussuscepção e dor abdominal. Em contrapartida, os pólipos gástricos tendem a ser sésseis. A presença de pólipos também pode se dar em outros locais anatômicos, como narinas, brônquios, trato biliar e bexiga.

$\mathrm{Na}$ SPJ percebe-se, por meio da análise histopatológica, que os pólipos apresentam uma proliferação de músculo liso, este que se estende para a lâmina própria, conferindo-lhe uma conformação arboriforme. Além disso, o epitélio sobrejacente costuma ser normal e respectivo ao tecido epitelial do trato gastrointestinal onde o pólipo situa-se. Ao exame endoscópico, podem ser visualizados pólipos sésseis, pedunculados ou lobulados. O paciente com SPJ pode apresentar desde lesões solitárias até mais de 20 pólipos por segmento intestinal, sendo que o tamanho destes pode variar de 1 milímetro a mais de 5 centímetros de diâmetro. Os primeiros pólipos surgem na primeira década de vida, gerando manifestações sintomáticas entre 10 e 30 anos de idade 3 .

As principais manifestações clínicas são decorrentes dos pólipos no trato gastrointestinais e variam entre episódios recorrentes de dor abdominal, devido a quadros de intussuscepção (também denominada invaginação intestinal) ou obstrução intestinal, além de sangramento intestinal inexplicado gerando anemia ferropriva, prolapso de pólipo retal, irregularidade menstrual e puberdade precoce devido a um estado de hiperestrogenismo por tumor de cordão sexual, fato que será comentado posteriormente. Dessa forma, muitos pacientes apresentam sintomas abdominais antes dos 20 anos de idade, principalmente por conta de intussuscepção ou obstrução intestinal, eventos que ocorrem em $50 \%$ dos pacientes antes da terceira década de vida ${ }^{5}$.

O tamanho do pólipo é o fator de risco mais importante para intussuscepção com obstrução intestinal, fato que ocorre principalmente em intestino delgado e pólipos com diâmetro maior ou igual a 15 milímetros apresentam potencial para gerar episódio de invaginação intestinal. Consequentemente, pólipos que apresentam crescimento acelerado, com diâmetro entre 10 e 15 milímetros ou sintomáticos devem ser removidos para evitar complicações futuras ${ }^{6}$.

Em um estudo feito por Hind et al..$^{5}$ conclui-se que aproximadamente $30 \%$ dos pacientes com SPJ necessitaram de intervenção por laparotomia antes dos 10 anos de idade e $68 \%$ antes dos 18 anos de idade. Além disso, 70\% das laparotomias iniciais foram realizadas por conta de obstrução intestinal ${ }^{2}$.

\section{SPJ e neoplasias}

Sabe-se que a SPJ predispõe o desenvolvimento de neoplasias malignas, dessa forma pacientes com tal síndrome apresentam maior probabilidade de desenvolvimento de câncer gastrointestinal, principalmente adenocarcinoma, e também em sítios extra-intestinais. $\mathrm{O}$ mecanismo de carcinogênese na SPJ ainda é incerta, mas alguns estudos evidenciaram o desenvolvimento sequencial hamartoma-adenoma-carcinoma em pólipos gástricos, de intestino delgado e de região colorretal em pacientes com a síndrome. Além disso, grandes hamartomas frequentemente apresentam focos de diferenciação adenomatosa e há evidências de que pacientes com SPJ são propensos ao desenvolvimento de pólipos adenomatosos, além dos hamartomatosos ${ }^{7}$.

O risco de desenvolvimento de câncer gastrointestinal na SPJ aumenta com o decorrer da idade, por isso o rastreamento e a polipectomia gastrointestinal são importantes para reduzir o risco de malignidade. $\mathrm{Na}$ Tabela 1 é possível analisar o risco acumulado de desenvolvimento de câncer em cada sítio, além da média idade de diagnóstico.

Os principais sítios de acometimento por lesão maligna no paciente com SPJ são, em ordem de risco, região colorretal, mama, pâncreas, aparelho ginecológico, intestino delgado, pulmão e região gastroesofagiana. $\mathrm{O}$ risco de desenvolvimento de qualquer tipo de câncer no paciente com SPJ na idade de 20, 30, 40, 50, 60 e 70 anos é de $1 \%, 3 \%, 19 \%, 32 \%, 63 \%$ e $81 \%$, respectivamente ${ }^{1}$.

Tabela 1. Risco acumulado de câncer na SPJ

\begin{tabular}{l|c|c}
\hline $\begin{array}{l}\text { Sítio de } \\
\text { acometimento }\end{array}$ & Risco na SPJ & $\begin{array}{c}\text { Média da idade ao } \\
\text { diagnóstico } \\
\text { (em anos) }\end{array}$ \\
\hline Região colorretal & $39 \%$ & $42-46$ \\
\hline Estômago & $29 \%$ & $30-40$ \\
\hline Intestino delgado & $13 \%$ & $37-42$ \\
\hline Pâncreas & $11-36 \%$ & $41-52$ \\
\hline Mama & $32-54 \%$ & $37-59$ \\
\hline Ovário & $21 \%$ & 28 \\
\hline Útero & $9 \%$ & 43 \\
\hline Cérvix & $10 \%$ & $34-40$ \\
\hline Testículo & $9 \%$ & $6-9$ \\
\hline Pulmão & $7-17 \%$ & 47 \\
\hline
\end{tabular}

Fonte: The American Journal of Gastroenterology, 2015. 
Okida LFA, et al. Síndrome de Peutz-Jeghers e acalásia: relato de caso e revisão da literatura.

Em relação aos tumores associados ao gênero, mulheres com SPJ podem apresentar tumor ovariano de cordões sexuais com túbulos anulares, o qual é benigno, mas pode se tornar maligno em $20 \%$ dos casos, tumor mucinoso ovariano e adenocarcinoma bem-diferenciado cervical (adenoma malignum). Enquanto isso, 9\% dos homens com SPJ desenvolvem tumor calcificante de células grandes de Sertoli nos testículos, o qual pode se malignizar em 10 a 20\% dos casos. Em alguns casos, na presença de tumor testicular benigno pode ocorrer feminilização ${ }^{1}$.

\section{Rastreamento}

Os guidelines para rastreamento de lesões malignas na SPJ é empírico e baseado nos riscos de complicações gastrointestinais e desenvolvimento de câncer. Para cada provável sítio de acometimento deve-se fazer um exame específico em um intervalo de tempo pré-determinado, podendo variar em alguns casos. A Tabela 2 mostra o sítio de investigação, a idade de início de rastreio, o intervalo do rastreio e o método de rastreio.

Tabela 2. Recomendação de rastreio na SPJ

\begin{tabular}{l|c|c|l}
\hline Sítio & $\begin{array}{c}\text { Idade de início de rastreio } \\
(\mathrm{em} \text { anos })\end{array}$ & $\begin{array}{c}\text { Intervalo de rastreio } \\
(\mathrm{em} \text { anos })\end{array}$ & Método de rastreio \\
\hline Cólon & $8,18^{*}$ & 3 & Colonoscopia \\
\hline Estômago & $8,18^{*}$ & 3 & Esofagogastroduodenoscopia \\
\hline $\begin{array}{l}\text { Intestino } \\
\text { Delgado }\end{array}$ & $8,18^{*}$ & 3 & Vídeocápsula Endoscópica \\
\hline Pâncreas & 30 & $1-2$ & Colangiopancreatografia por RM \\
\hline Mama & 25 & 1 & $\begin{array}{l}\text { - Auto-exame anual (início aos 18 anos); } \\
\text { - RM de mama (anual) }\end{array}$ \\
\hline Ovário & 25 & 1 & - e/ou mamografia (início aos 25 anos) \\
\hline Endométrio & 25 & 1 & $\begin{array}{l}\text { - Exame pélvico } \\
\text { - USG pélvico ou transvaginal; } \\
\text { - CA-125 provavelmente pouco útil }\end{array}$ \\
\hline Cérvix & 25 & 1 & $\begin{array}{l}\text { - Exame pélvico } \\
\text { - USG pélvico ou transvaginal }\end{array}$ \\
\hline
\end{tabular}

* De acordo com Beggs et al. ${ }^{1}$, iniciar rastreio aos 8 anos de idade; se pólipos presentes, repetir a cada 3 anos; se pólipos ausentes, repetir aos 18 anos de idade, e então repetir a cada 3 anos, ou antes caso sintomas apareçam.

Fonte: adaptado de The American Journal of Gastroenterology, 2015.

\section{Métodos de rastreio gastrointestinal}

$\mathrm{O}$ rastreamento rotineiro de intestino delgado em pacientes com SPJ é recomendada para reduzir a chance de manifestações clínicas por pólipos, diminuindo a necessidade de intervenção cirúrgica repetida, bem como propiciar um diagnóstico precoce de lesões malignas ou, ao menos, prevenir a transformação de lesões benignas ou pré-malignas naquelas com malignidade. Entre os métodos de rastreio intestinal estão a videocápsula endoscópica, enteroscopia de balão duplo, enterografia ou enteróclise por tomografia computadorizada multislice e enterografia ou enteróclise por ressonância magnética ${ }^{6}$.
A ressonância magnética $(\mathrm{RM})$ tem sido utilizada ultimamente para avaliação de intestino delgado em várias situações clínicas e tem sido considerada um importante método para detecção de tumores em tal órgão. Há basicamente dois métodos de realização. Na enterografia por RM a administração do contraste é por via oral, enquanto que na enteróclise por RM a administração é realizada por uma sonda nasojejunal. Alguns estudos sugerem que a enterografia por RM apresentou resultado satisfatório na detecção de pólipos em pacientes com SPJ em comparação à cápsula endoscópica, enteroscopia por balão e enteroscopia intraoperatória. Assim, enterografia por RM não apresenta radiação, é menos dispendiosa do 
que exames como a cápsula endoscópica e mais acurada para identificação de pólipos de maior diâmetro.

A enterografia por tomografia computadorizada multislice (ou Multidetector Computed Tomography MDCT) ou enteróclise por MDCT são utilizadas para detecção de tumores de intestino delgado e rastreamento em pacientes com SPJ. No entanto, quadros de intussuscepção ou obstrução de intestino delgado podem ser bem diagnosticadas por tomografia computadorizada multislice abdominal normal.

A enteroscopia de balão duplo é um método que permite a avaliação completa do intestino delgado e vem sendo utilizada desde 2001. Por meio deste, é possível a realização de intervenção diagnóstica e terapêutica em um mesmo procedimento, permitindo a remoção endoscópica de pólipos proximais e distais de intestino delgado acima de 10 milímetros.

O uso da videocápsula endoscópica é livre de radiação e apresenta poucas complicações. Além disso, trata-se de um método que vem apresentando vantagens na avaliação de sangramento oculto gastrointestinal. Todavia, diferentemente da enteroscopia de balão duplo, não é possível a realização de intervenção terapêutica, somente diagnóstica. Alguns estudos demonstraram que algumas lesões de importância clínica significativa podem não ser evidenciadas com a videocápsula endoscópica, principalmente aquelas situadas em intestino delgado proximal. Tal fato se deve pela efêmera passagem por tal região, pela presença de artefatos de bolhas e por pouca distensão luminal relativa.

Dessa maneira, em relação aos métodos de rastreamento de lesões em intestino delgado, a RM ou MDCT por enterografia ou enteróclise conseguem detectar a maioria dos pólipos nos pacientes com SPJ, podendo não evidenciar pólipos menores que 10 milímetros de tamanho, porém que não apresentam significado clínico ${ }^{6}$.

\section{Tratamento}

O tratamento da SPJ abrange a remoção de pólipos no trato gastrointestinal e, em quadros de maior severidade, como intussuscepção ou obstrução intestinal, normalmente a terapêutica é por meio de intervenção cirúrgica.

Por meio da endoscopia digestiva alta (EDA) e colonoscopia é possível a polipectomia. O ideal seria a retirada de todos os pólipos, porém nem sempre é possível e ainda poderia trazer consequências negativas para o paciente. Em alguns casos, a colectomia é necessária para o controle da polipose colônica, devendo ser realizada especialmente quando há transformação maligna nestes pólipos. Nos quadros de intussuscepção, a abordagem cirúrgica é usualmente necessária e deve incluir um exame minucioso de todo o intestino delgado, a fim de eliminar qualquer pólipo que possa promover complicação futura.

A endoscopia intraoperatória normalmente auxilia na remoção de pólipos, principalmente aqueles localizados no estômago e duodeno e que apresentam tamanho significativo.

\section{Acalásia e SPJ}

A acalásia é uma doença rara que acomete $1 \mathrm{a}$ cada 100.000 indivíduos, normalmente entre 25 e 60 anos, caracterizada pela perda de células ganglionares existentes no plexo mioentérico esofágico. Pode haver um acometimento dos neurônios ganglionares excitatórios, bem como dos inibitórios. Estes são responsáveis pelo relaxamento do esfíncter esofágico inferior durante a deglutição e pela propagação peristáltica do alimento. Desse modo, a ausência de tais neurônios provoca uma falha no relaxamento dessa musculatura e na aperistalse esofágica.

O paciente com acalásia pode apresentar determinados sintomas, como disfagia a alimentos sólidos e líquidos, regurgitação, dor torácica e emagrecimento. Além disso, em situações de acalásia avançada, pode haver bronquite, pneumonia ou abscesso pulmonar como consequência da regurgitação esofágica e broncoaspiração crônica.

A acalásia pode ser idiopática, mas há situações que devem ser consideradas como diagnóstico diferencial, incluindo espasmo esofágico difuso, doença de Chagas e pseudo-acalásia. Existem hipóteses que relacionam tal condição patológica, quando considerada idiopática, a um processo autoimune decorrente de uma infecção latente pelo herpesvírus humano tipo I que causaria da degeneração de células ganglionares esofágicas.

$\mathrm{Na}$ doença de Chagas, o contato sanguíneo com as fezes do artrópode (popularmente conhecido como "barbeiro") propicia a infecção por um protozoário, o Trypanosoma cruzi. Ao se tratar de uma doença crônica, anos após a infecção pode ocorrer destruição das células ganglionares autonômicas do organismo, incluindo esôfago, coração, intestino, trato urinário e via respiratória. Dessa forma, gera-se alteração na contratilidade esofágica, gerando também quadro de disfagia e demais sintomas podem estar presentes.

Em alguns casos de carcinoma de fundo gástrico ou de esôfago distal, pode ocorrer uma infiltração tumoral e simular um quadro de acalásia idiopática. Tal condição ocorre mais em idosos e os sintomas iniciam em um intervalo de tempo menor que um ano, havendo emagrecimento.

O diagnóstico de acalásia é feito por radiografia de deglutição de bário, mas, principalmente, pela manometria esofágica. A endoscopia é importante para afastar a hipótese de uma neoplasia estar gerando um quadro de pseudoacalásia. Nas radiografias contrastadas nota-se dilatação esofágica com esvaziamento incompleto, nível hidroaéreo e afilamento na região do esfíncter esofágico inferior. $\mathrm{Na}$ 
esofagomanometria, os critérios para acalásia incluem o não relaxamento induzido do esfíncter esofágico inferior e ausência de peristalse.

É importante saber que a acalásia não pode ser evitada ou revertida por qualquer intervenção terapêutica. Raramente a peristalse retorno à normalidade. No entanto, para melhora dos sintomas, a pressão do esfíncter esofágico inferior pode ser reduzida por meio da dilatação pneumática por endoscopia ou cirurgia. Os medicamentos utilizados são nitratos, bloqueadores de canal de cálcio e toxina botulínica, mas esses são pouco eficazes. Outros métodos não farmacológicos são a dilatação pneumática e miotomia laparoscópica de Heller, que são tratamentos mais duradouros ${ }^{8}$.

Em relação à SPJ, não há relato, até o momento, na literatura médica de pacientes com essa doença apresentando concomitantemente acalásia. No paciente em questão, após ter sido submetido a várias cirurgias para correções de intussuscepção, ocorreu um quadro de disfagia de condução com perda de peso. Levantou-se a suspeita de acalásia e os métodos diagnósticos confirmaram a hipótese. Levando em conta que o paciente não apresentava fatores de risco para o da doença de Chagas, bem como a endoscopia digestiva alta não evidenciou nenhuma infiltração tumoral,

\section{REFERÊNCIAS}

1. Syngal S, Brand RE, Church JM, Giardello FM, Hampel HL, Burt RW, et al. ACG Clinical Guideline: genetic testing and management of hereditary gastrointestinal cancer syndromes. Am J Gastroenterol. 2015;110(2):223-62; quis 63. doi: 10.1038/ajg.2014.435.

2. Meserve EEK, Nucci MR. Peutz-Jeghers syndrome: pathobiology, pathologic manifestations, and suggestions for recommending genetic testing in pathology Reports. Surg Pathol Clin. 2016;9(2):243-68. doi: 10.1016/j. path.2016.01.006.

3. Giardiello FM, Trimbath JD. Peutz-Jeghers syndrome and management recommendations. Clin Gastroenterol Hepatol. 2006;4:408-415. doi: 10,1016/J.CGH.2005.11.005.

4. Alves LL, Lemos LVB, Barreto LA, Barreto JCC, Duncan LR, Pereira SM. Peutz Jeghers: relato de caso. Rev Cient Fac Med Campos. 2012;8:16. provavelmente tratava-se de uma acalásia idiopática. Dessa forma, é provável que nesse paciente a associação entre a SPJ e acalásia tenha sido apenas coincidente, não apresentado relação causal.

\section{CONCLUSÃO}

Neste caso apresentado, o paciente apresentou as principais características da SPJ, que são máculas hipercrômicas mucocutâneas, pólipos no trato gastrointestinal, história familiar da doença, além de complições mais severas, como dois episódios de intussuscepção, que demandaram tratamento cirúrgico com realização de enterectomia segmentar. No entanto, o surgimento concomitante de acalásia não parece ter tido relação com a SPJ, até porque não há nenhuma associação relatada ou comentada na literatura médica. Dessa forma, é importante submeter o paciente com SPJ ao rastreamento de neoplasias malignas de acordo com as recomendações abordadas, bem como, se possível, pesquisar a mutação do gene STK11 nos familiares para que o acompanhamento e prevenção de câncer possam ocorrer de forma adequada. Este é o primeiro caso na literatura mundial da associação da SPJ com acalásia idiopática.

5. Tomas C, Soyer P, Dohan A, Dray X, Boudiaf M, Hoeffel C. Update on imaging of Peutz-Jeghers syndrome. World J Gastroenterol. 2014;20(31):10864-75. doi: 10.3748/wjg. v20.i31.10864.

6. Hinds R, Philp C, Hyer W, Fell JM. Complications of childhood Peutz-Jeghers syndrome: implications for pediatric 24 screening. J Pediatr Gastroenterol Nutr. 2004;39:219-20. doi: 10.1097/00005176-200408000-00027.

7. McGarrity TJ, Kulin HE, Zaino RJ. Peutz-Jeghers syndrome. Am J Gastroenterol. 2000;95:596-604. doi: 10.1111/j.15720241.2000.01831.x.

8. Longo DL, Fauci AS, Kasper DL, Hauser SL, Jameson JL, Loscalzo J. Medicina interna de Harrison. 18a ed. Porto Alegre: AMGH; 2013. 